\title{
Artigos
}

\section{O ritual da interpelação ideológica no Turismo LGBT e a impossibilidade do desejo que se desloca*}

\section{The ritual of ideological interpellation in LGBT Tourism and the impossibility of the desire that moves}

\section{El ritual de la interpelación ideológica en el Turismo LGBT y la imposibilidad del deseo que se desplaza}

\section{Maicon Gularte Moreiraㄹ; Luciene Jung de Campos $^{1}$}

1 Universidade de Caxias do Sul (UCS), Rio Grande do Sul, Brasil.

\section{Palavras-chave:}

Turismo;

Análise do Discurso;

LGBT;

Ideologia;

Desejo.

Keywords:

Tourism;

Discourse Analysis;

LGBT;

Ideology;

\begin{abstract}
Resumo
No Turismo, as produções acadêmicas existentes sobre o segmento de Turismo LGBT têm validado práticas do mercado e apresentado, exclusivamente, como justificativas para esse tipo de segmentação, a definição de um perfil econômico desses sujeitos. Neste trabalho temos como objetivo a problematização do segmento de Turismo LGBT com base na análise dos mecanismos de interpelação do sujeito LGBT como um turista LGBT. Questiona o modo como a oferta de produtos se dá pelo mercado turístico às pessoas LGBT, frequentemente com apelo ao sexo. Não se furta, contudo, de reconhecer a busca pelo prazer sexual através dos deslocamentos turísticos, apenas se propõe à exposição dos mecanismos de controle do desejo dos sujeitos LGBT através de sua interpelação como turistas LGBT. Para isso, assume o folheto promocional da campanha "iTRAE TUS COLORES!" como a materialidade de onde quatro sequências discursivas são tomadas para compor o corpus de análise. Esta campanha, apoiada pelo Instituto Brasileiro de Turismo (EMBRATUR), promoveu o Brasil como um destino turístico LGBT em dezembro de 2014 nas cidades de Madrid e Valência, na Espanha. A análise do folheto promocional se filia aos pressupostos teórico-metodológicos da Análise de Discurso francesa teorizada por Michel Pêcheux, que articula conceitos oriundos de três campos teóricos: Psicanálise, Materialismo Histórico e Linguística. Por isso, aproxima os conceitos de sujeito e ideologia para discutir os mecanismos pelos quais a ideologia interpela esses sujeitos, autorizando alguns sentidos ao seu desejo inconsciente e desautorizando outros. Este processo, responsável por identificar o sujeito e censurar o desejo, produz deslocamentos de ordem psíquica e física, interpretados aqui como a busca pela realização do desejo através das viagens. Assumindo, portanto, que a impossibilidade de tomar uma posição, bem como de inscrever o desejo, é o que promove o deslocamento do sujeito, a pesquisa faz um retorno no campo do Turismo.
\end{abstract}

\section{Abstract}

In Tourism, the existing academic literature on LGBT tourism segment have validated marke practices and presented, exclusively, as justification for this type of segmentation, the definition of an economic profile of these subjects. In this paper, we aim to problematize the LGBT Tourism segment based on the analysis of the mechanisms of interpellation of the LGBT subject as an LGBT tourist. It questions the way tourism products are promoted to

\footnotetext{
* Este trabalho teve sua versão original apresentada e premiada em $1^{\circ}$ lugar no GT Mestre Destaque do XV Seminário Anual da Associação Nacional da Pesquisa e Pós-graduação em Turismo (ANPTUR).
} 
Desire.

\section{Palabras clave:}

Turismo;

Análisis del Discurso;

LGBT;

Ideología;

Deseo.

Revisado por pares.

Recebido em: 18/10/2018.

Aceito em: 22/11/2018.
LGBT people, often alluding to sex. However, it does not shy away from recognizing the search for sexual pleasure through tourist movements, but only proposes to expose the mechanisms of control of the desire of LGBT subjects through their interpellation as LGBT tourists. To do this, it takes the promotional brochure of the campaign "iTrae tus Colores!" as the materiality from which four discursive sequences are taken to compose the analysis corpus. This campaign, supported by the Brazilian Tourism Institute (EMBRATUR), promoted Brazil as an LGBT tourist destination in December 2014 in the cities of Madrid and Valencia, Spain. The analysis of the promotional brochure is based on the theoretical and methodological assumptions of the French Discourse Analysis theorized by Michel Pêcheux, who articulates concepts from three theoretical fields: Psychoanalysis, Historical Materialism, and Linguistics. Therefore, the author brings together the concepts of subject and ideology to discuss the mechanisms by which ideology interpellates these subjects, allowing some meanings to their unconscious desire and disallowing others. This process, responsible for identifying the subject and censoring desire, produces psychic and physical displacements, interpreted here as the search for the realization of desire through travel. Assuming, therefore, that the impossibility of taking a position, as well as inscribing the desire, is what promotes the displacement of the subject, the research returns to the field of Tourism.

\section{Resumen}

En el Turismo, las producciones académicas existentes sobre el segmento de Turismo LGBT han validado prácticas del mercado y presentado, exclusivamente, como justificaciones para ese tipo de segmentación, la definición de un perfil económico desales sujetos. En este trabajo tenemos como objetivo la problematización del segmento de Turismo LGBT con base en el análisis de los mecanismos de interpelación del sujeto LGBT como un turista LGBT. Cuestiona el modo como la oferta de productos se da por el mercado turístico a las personas LGBT, frecuentemente, con Ilamamiento al sexo. No se hurta, pero, de reconocer la búsqueda por el placer sexual a través de los desplazamientos turísticos, sólo se propone a la exposición de los mecanismos de control del deseo de los sujetos LGBT a través de su interpelación como turistas LGBT. Para eso, asume el folleto promocional de la campaña "iTRAE TUS COLORES!" como la materialidad de donde cuatro secuencias discursivas son tomadas para componer el corpus de análisis. Esta campaña, apoyada por el Instituto Brasileño de Turismo (EMBRATUR), promovió lo Brasil como un destino turístico LGBT en diciembre de 2014 en las ciudades de Madrid y Valencia, en España. El análisis del folleto promocional se filia a los presupuestos teórico-metodológicos del Análisis de Discurso francesa teorizada por Michel Pêcheux, que articula conceptos oriundos de tres campos teóricos: Psicoanálisis, Materialismo Histórico y Lingüística. Por eso, aproxima los conceptos de sujeto e ideología para discutir los mecanismos por los cuales la ideología interpela esos sujetos, autorizando algunos sentidos a su deseo inconsciente y desautorizando otros. Este proceso, responsable por identificar el sujeto y censurar el deseo, produce desplazamientos de orden psíquica y física, interpretados aquí como la búsqueda por la realización del deseo a través de los viajes. Asumiendo, por lo tanto, que la imposibilidad de tomar una posición, así como de inscribir el deseo, es lo que promueve el desplazamiento del sujeto, la investigación hace uno retorno en el campo del Turismo.

Como citar: Moreira, M. G.; Campos, L. G. (2019). 0 ritual da interpelação ideológica no Turismo LGBT e a impossibilidade do desejo que se desloca. Revista Brasileira de Pesquisa em Turismo, São Paulo, 13 (2), p. 54 - 68, maio/ago. http://dx.doi.org/10.7784/rbtur.v13i2.1542

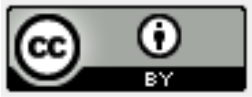

\section{REFLEXÕES INICIAIS}

No Turismo, as produções acadêmicas existentes sobre a segmentação de mercado LGBT (Lésbicas, Gays, Bissexuais, Travestis e Transexuais) têm validado práticas do mercado e apresentado, exclusivamente, como justificativas para esse tipo de segmentação, a definição de um perfil econômico dos sujeitos LGBT. Segundo tais definições, os LGBT são mais escolarizados e com maior renda em relação à média da população, não possuem filhos e, consequentemente, têm mais tempo e dinheiro disponível para a realização de atividades de turismo e lazer (Angeli, 1999; Oliveira, 2002; Avena, \& Rossetti, 2004; Trevisan, 2006; Dias, Oliveira, Lucian, Barbosa, \& Kovacs, 2009; Sanches, Mancini, \& Nascimento, 2011). Outras referências existentes, conhecidas no campo do Turismo LGBT, estão desatualizadas em relação ao entendimento atual sobre determinados temas que envolvem os estudos de gênero e sexualidade como, por exemplo, que "o Brasil não é um país homófobos" (Avena, \& Rossetti, 2004, p. 14), homossexualidade como uma "espécie" biológica (Chiochetta, \& Avena, 2006, p. 17) e, ainda, identidade de gênero e orientação sexual como sinônimos (Oliveira, 2016). Nessa direção, Tadioto (2016, p. 40) propõe que "a discussão sobre os segmentos na academia é apenas uma reprodução dos resultados observados nas pesquisas de mercado, sem a devida reflexão crítica esperada". É preciso reconhecer, no entanto, que nem todas as referências realizadoras da articulação temática entre a população LGBT e o Turismo apresentam abordagem 
estritamente mercadológica, lançando outros olhares sobre o tema (Trigo, 2009; Lanzarini, 2013; Moreira, \& Hallal, 2017).

Por sua vez, as práticas de mercado, já validadas pela academia, produzem mais dados em torno desse perfil, criando um estereótipo deturpado sobre os sujeitos LGBT. Em consequência, campanhas publicitárias turísticas voltadas às pessoas LGBT, realizam uma oferta exagerada e apelativa em torno da possibilidade de realização do ato sexual. Ambos, academia e mercado, retroalimentam-se nos dizeres. Assim compreendido, tanto mercado quanto academia não possuem como alvo a inclusão do sujeito LGBT, suas demandas históricas, sociais, políticas e culturais contingenciadas, mas o potencial retorno financeiro que a promessa de inclusão social pode lhe gerar, seu pink ${ }^{\dagger}$ money . Isso ocorre, sobretudo, por causa da abordagem dominante no campo de estudos do Turismo, que o enxerga, antes de tudo, como um produto (Moesch, 2000).

0 momento atual é outro, outras demandas relacionadas às diversidades sexuais e de gêneros ganharam visibilidade, nos impondo a necessidade de produzir outros sentidos sobre as possibilidades de existência desses sujeitos. Neste trabalho temos como objetivo problematizar o segmento de Turismo LGBT (Lésbicas, Gays, Bissexuais, Travestis e Transexuais) com base na análise dos mecanismos de interpelação do sujeito LGBT como um turista LGBT. Questiona-se o modo como a oferta de produtos pelo mercado turístico se dá às pessoas LGBT, frequentemente, com apelo ao sexo. Não se trata, contudo, de negar a busca pelo prazer sexual através dos deslocamentos turísticos, mas de expor os mecanismos de controle do desejo dos sujeitos LGBT através de sua interpelação como turistas LGBT.

Para esta pesquisa, portanto, partimos do pressuposto de que não há uma pergunta apenas capaz de orientar a análise, uma vez que entendemos ser necessária a problematização do modo como ocorre a segmentação do Turismo LGBT, ou seja, realizar questões a esse respeito e não, necessariamente, as responder. Assim, orientaremos a presente exposição a partir do entrelaçamento de nosso referencial teórico com a materialidade, com a análise e com as questões que emergem na medida em que o texto se desenvolve. Ao final, esperamos ter possibilitado a exposição dos processos de identificação e interpelação dos sujeitos LGBT com a e pela materialidade, bem como evidenciado as contradições inerentes a esse processo.

\section{ORIENTAÇÕES TEÓRICAS E METODOLÓGICAS DO DISPOSITIVO DE ANÁLISE}

Antes da exposição analítica, necessitamos apresentar o dispositivo teórico e metodológico que a orienta. A Análise do Discurso (AD) de que falamos, é aquela proposta pelo filósofo francês Michel Pêcheux e cujo objeto, o discurso, é compreendido como um "efeito de sentidos" entre "lugares determinados na estrutura de uma formação social" (Pêcheux, 2014a, p. 81). Sendo o discurso compreendido desse modo, o que se busca nessa linha de análise é o funcionamento da língua fazendo sentido, o modo como o texto significa, e não o que ele significa (Orlandi, 2010).

Para isso, Pêcheux irá reunir três campos teóricos distintos, que já estavam produzindo os efeitos de sentido que desejava: o Materialismo Histórico guiado por Louis Althusser em sua releitura da obra de Karl Marx, "como teoria das formações sociais e de suas transformações, compreendida aí a teoria das ideologias" (Pêcheux, \& Fuchs, 2014, p. 160); a Psicanálise freudiana reatualizada por Jacques Lacan, enquanto "teoria da subjetividade" do sujeito (Pêcheux \& Fuchs, 2014, p. 160); e os aspectos não reducionistas da linguagem, oriundos do apogeu do movimento estruturalista daquela época (Henry, 2014) tendo a Linguística saussuriana como "teoria dos mecanismos sintáticos e dos processos de enunciação" (Pêcheux \& Fuchs, 2014, p. 160).

Nesse entremeio, Althusser (2003) vai afirmar que "só há prática através de e sobre uma ideologia" (p. 93) e que, portanto, os indivíduos são desde sempre interpelados como sujeitos. 0 deslocamento da noção de indivíduo para a de sujeito, constituído na relação com o simbólico através da história, será, portanto, a contribuição da Psicanálise, uma vez que esse sujeito afetado pelo real da história e da língua, não possui o "controle sobre os modos como elas o afetam. Isso redunda em dizer que o sujeito discursivo funciona pelo

\footnotetext{
† Termo utilizado no mercado e na academia para designar o dinheiro utilizado pelos sujeitos LGBT e, mais genericamente, para se referir aos próprios consumidores LGBT.
} 
inconsciente e pela ideologia" (Orlandi, 2010, p. 20). Nessa linha de análise, portanto, Pêcheux (2014b) irá considerar como o sujeito do discurso aquele interpelado pela ideologia para que a língua faça sentido, para que possa dizer e ser dito, não havendo discurso sem sujeito, nem sujeito sem ideologia.

Logo, a partir da reflexão de Campos (2010, p. 41), que propõe, sob a perspectiva althusseriana, pensarmos na publicidade/propaganda "como um ritual de interpelação ideológica do sistema dominante, uma prática de manutenção e reprodução do capitalismo", tomamos como materialidade de análise o folheto da campanha promocional "iTrae tus Colores!" (Guiya Editora, 2014). Esta campanha, apoiada pelo Instituto Brasileiro de Turismo (EMBRATUR), promoveu o Brasil como um destino turístico LGBT em dezembro de 2014 nas cidades de Madrid e Valência, na Espanha. Tomamos essa campanha como objeto de análise em razão do período em que o curso da pesquisa em questão teve início. Consequentemente, os dados e informações que serão utilizados ao longo do texto possuem como limite e contexto temporal o período de realização da campanha.

Reconhecemos, mesmo assim, que os olhares interpretativos e reflexivos sobre a materialidade e sobre este texto, especificamente, não se limitam ou desconsideram contextos mais atuais a partir do ano de 2015. Reconhecemos, ainda, que o material promocional analisado foi produzido pela Guiya Editora através de parceria com a Palco - Comparsaria Primeira de Talentos (Guiya Editora, n.d., n.p.). Essa última, por sua vez, na época da campanha, é que possuía contrato com o Governo Federal. As condições de produção do material promocional, portanto, são múltiplas e atravessadas por distintos lugares na estrutura da formação social, lugares sobre os quais não possuímos o controle e cujas evidências dos sentidos não são totalmente transparentes a nós. Por essa razão, o dispositivo selecionado para a elaboração deste trabalho justifica-se, também, porque nos permite assumir que a interpretação e análise se dá na relação entre analista e materialidade, relação que não visa dominar os sentidos em jogo, mas aproximar-se dos processos de sua construção.

Nessa linha, o analista do discurso é o responsável pela construção do seu próprio dispositivo de análise, orientado pelos pressupostos teóricos e metodológicos que servem como seu suporte, mas não apenas. A análise inicia ao mesmo tempo em que inicia o processo de definição do corpus, diante das especificidades características da materialidade de análise, do objetivo e do próprio percurso do analista. A teoria irá apenas conduzir "a relação do analista com o seu objeto, com os sentidos, com ele mesmo, com a intepretação" (Orlandi, 2010, p. 64). Ou seja, a análise é sempre a análise do analista diante de suas condições de produção.

Assim, ao longo do processo de análise, surge a demanda de um "ir-e-vir constante entre teoria, consulta ao corpus e análise" (Orlandi, 2010, p. 67). Esse processo de deslizamentos realizados pelo analista é o que permite a ele, a partir de um gesto interpretativo e de descrição, formular outras possibilidades de dizer aquilo que está enunciado em sua materialidade e, com isso, apreender o processo de produção de sentidos, pois haverá “sempre um 'outro' possível que o constitui” (Orlandi, 2010, p. 79), um outro sentido possível. Nesse retorno contínuo da materialidade para o dispositivo teórico, "o analista tece as intrincadas relações do discurso, da língua, do sujeito, dos sentidos, articulando ideologia e inconsciente” (Orlandi, 2010, p. 80). Assim, delineia-se o processo metodológico desta análise.

Em razão dos movimentos de leitura e interpretação que estabelecemos na relação com a materialidade de análise, buscamos, deste modo, pensar sobre o conjunto das formações imaginárias que os deslizamentos realizados permitiram inferir, a partir do conceito proposto por Pêcheux (2014a). Assume-se este conceito em razão do objetivo de problematizar os modos de interpelação do sujeito LGBT em turista LGBT, ou seja, o jogo de forças (e de sentidos) que envolve a produção dessa interpelação (simbólica) pela identificação (imaginária) do sujeito com a materialidade, sem determinar quem ou o que ocupa o lugar de enunciação. Ao interpretar este conceito, Campos (2010) diz que as formações imaginárias:

[...] se manifestam no processo discursivo através da antecipação das relações de força e de sentido. $\mathrm{Na}$ antecipação, o emissor projeta uma representação imaginária do receptor. A partir dessa representação estabelece suas estratégias discursivas, num jogo espelhado dos sujeitos com os lugares reservados na estrutura da formação social que determinam as condições de produção discursivas, definindo o lugar ocupado pelos sujeitos no discurso. ( $p$. 92) 
O sujeito na $\mathrm{AD}$ é essa tomada de posição (simbólica), feita a partir de uma identificação (imaginária). Identificação imaginária porque é aquela a partir da qual o sujeito é alienado pelo jogo de evidências, de si e dos sentidos, produzidos pelo seu assujeitamento. Para Pêcheux (2014a, p. 81), as formações imaginárias podem ser entendidas como os "lugares determinados na estrutura de uma formação social, [...] marcados por propriedades diferenciais determináveis" e que estão "representados nos processos discursivos em que são colocados em jogo". Ou seja, o que funciona é "uma série de formações imaginárias que designam o lugar que A e B se atribuem cada um a si e ao outro, a imagem que eles se fazem de seu próprio lugar e do lugar do outro" (Pêcheux, 2014a, p. 82), conforme demonstrado no Quadro 1.

\begin{tabular}{|c|c|c|c|}
\hline \multicolumn{2}{|c|}{$\begin{array}{l}\text { Expressão que designa as for- } \\
\text { mações imaginárias }\end{array}$} & Significação da expressão & $\begin{array}{l}\text { Questão implícita cuja "resposta" subentende } \\
\text { a formação imaginária correspondente }\end{array}$ \\
\hline \multirow{3}{*}{$A$} & $I_{A}(A)$ & $\begin{array}{l}\text { Imagem do lugar de A para o su- } \\
\text { jeito colocado em A }\end{array}$ & "Quem sou eu para Ihe falar assim?" \\
\hline & $I_{A}(B)$ & $\begin{array}{l}\text { Imagem do lugar de B para o } \\
\text { sujeito colocado em A }\end{array}$ & "Quem é ele para que eu lhe fale assim?" \\
\hline & $I_{A}(R)$ & "Ponto de vista" de A sobre R & “De que lhe falo assim?" \\
\hline \multirow{3}{*}{ B } & $\mathrm{IB}(\mathrm{B})$ & $\begin{array}{l}\text { Imagem do lugar de B para o } \\
\text { sujeito colocado em B }\end{array}$ & "Quem sou eu para que ele me fale assim?" \\
\hline & $\mathrm{I}_{\mathrm{B}}(\mathrm{A})$ & $\begin{array}{l}\text { Imagem do lugar de A para o su- } \\
\text { jeito colocado em B }\end{array}$ & "Quem é ele para que me fale assim?" \\
\hline & $\mathrm{I}_{B}(\mathrm{R})$ & "Ponto de vista" de B sobre R & "De que ele me fala assim?" \\
\hline
\end{tabular}

Fonte: Elaborado pelos autores, a partir de Pêcheux (2014a, pp. 82-83).

Pêcheux (2014a) considera a existência das formações imaginárias como pressuposto de todo processo discursivo, visto que elas resultam “[...] de processos discursivos anteriores (provenientes de outras condições de produção) que deixaram de funcionar, mas que deram nascimento a 'tomadas de posição' implícitas que asseguram a possibilidade do processo discursivo [...]" (p. 85). Logo, a apreensão do referente $(\mathrm{R})$, do outro (B) e de si mesmo (A) “é sempre atravessada pelo ‘já ouvido' e o ‘já dito', através dos quais se constitui a substância das formações imaginárias enunciadas” (Pêcheux, 2014a, p. 85).

Ao encontro do que colocamos em relação ao processo metodológico, entendemos que a exposição de alguns elementos teóricos iniciais se faz necessária, pois atravessam a leitura. Para o que necessitamos agora, partimos do enunciado de Indursky (2008) sobre o sujeito de que trata a AD. Segundo a autora, ele "não está na origem do dizer, pois é duplamente afetado. Pessoalmente e socialmente. Na constituição de sua psique, este sujeito é dotado de inconsciente. E em sua constituição social, ele é interpelado pela ideologia" (p. 10). Deste modo, precisamos nos aproximar das noções de sujeito do inconsciente e de ideologia, para que tenhamos condições de refletir sobre os lugares e os sentidos postos em jogo em nossas análises.

Ao acompanhar a incursão freudiana sobre o inconsciente e seu funcionamento, se supõe que o inconsciente não é um conceito pronto ou dado, mas que ele se mostra através do sujeito e, portanto, existe quando o sujeito falha, tropeça e/ou quando tudo aquilo que o sujeito não controla surge, emerge, ricocheteia em sua superfície. Conforme propõe a teoria psicanalítica, o sujeito falha porque é constituído por uma falta primordial que o faz desejar e, no momento em que a falta se instala, é quando o inconsciente se estrutura (Lacan, 2016).

A acepção do inconsciente como estrutura pertence a reinterpretação estruturalista de Lacan (2016) sobre a obra freudiana e sobre este conceito, significando que, para se inscrever no campo da linguagem, o sujeito precisou abrir mão de sua condição de completude primordial em relação à sua mãe, aonde nada Ihe faltava. Esta falta é, consequentemente, aquilo que causa o desejo, mas diferencia-se de uma necessidade. Esse desejo é o desejo de completude, ou seja, do (re)encontro com a mãe idealizada. Portanto, o objeto do 
desejo, ao mesmo tempo em que se esquiva e permanece oculto, porque não pode ser (re)encontrado, remete à própria causa do desejo (Lacan, 1992).

$\mathrm{Na}$ impossibilidade desse (re)encontro, o sujeito irá destinar suas pulsões para objetos que the demandem um baixo investimento de energia, ou seja, para outros objetos que lhe permitam a satisfação parcial do desejo, em detrimento daqueles objetos de alto investimento, ou seja, que the causem maior sofrimento pelo desejo primordial que não pode ser satisfeito (Freud, 1905/1996b). A este processo, em Psicanálise, dá-se o nome de deslocamento (Freud, 1901/1996c). Isso, de forma alguma, quer dizer que as experiências de deslocamento não podem gerar sofrimento, apenas que se apresentam como uma possibilidade de gratificação parcial de um desejo inconsciente.

O deslocamento, portanto, é o processo psíquico no qual conteúdos inconscientes podem se gratificar, manifestar, aparecer, gozar, ainda que parcialmente. O deslocamento será entendido por Lacan (1998, p. 515) como "o transporte da significação que a metonímia demonstra e que, desde seu aparecimento em Freud, é apresentado como o meio mais adequado do inconsciente para despistar a censura". Isso significa que o deslocamento é o transporte da significação do desejo primordial para um objeto de desejo, metonímico (Lacan, 1999), sobre o qual o sujeito pode alcançar alguma gratificação pulsional, para além daquilo que regula/censura o seu desejo. Aqui destaca-se a relação de poder existente entre censura, ideologia e desejo. Ou seja, o deslocamento psíquico é uma forma de resistência à interpelação do sujeito do inconsciente, através da qual o desejo é controlado.

Nesse sentido, o desejo inconsciente de reencontro com o objeto perdido possui, diretamente, relação com a ideologia e com a linguagem, pois a ideologia é responsável por regular/censurar as possibilidades de simbolizarmos nosso desejo e, com isso, de se apropriar dos objetos de gratificação parcial do desejo para dizer onde podemos gozar. Este gozar, no âmbito desta análise, pode significar muitas possibilidades de gratificação do desejo, como, por exemplo, viajar, consumir bens e serviços, quebrar o cotidiano, libertar-se, restaurar as energias, expressar sua sexualidade, ter suas cores "reconhecidas", etc.

O desejo, portanto, é interpretado aqui como aquilo que move o sujeito em direção a algo, a um objeto metonímico que marca esse desejo, mas que se diferencia de uma necessidade. Esta última é da ordem da satisfação, gerada por objetos correspondentes, como o alimento corresponde às necessidades nutricionais do corpo. 0 desejo é o desejo de sua realização, da ordem do recalcado, portanto, do não-sabido e só pode ser gratificado parcialmente através da realização alucinatória desse desejo, como nos sonhos ou pelo seu desdobramento na fantasia (Freud, 1900/1996a). Nesse eterno recortar-se e mover-se, o sujeito não se desloca só fisicamente no tempo e no espaço, mas se desloca fisicamente no tempo e no espaço em razão de um processo de deslocamento psíquico, um processo inconsciente que o faz mover-se em direção a algo, mesmo sem saber o quê.

A ideologia será compreendida como "uma 'representação' da relação imaginária dos indivíduos com suas condições reais de existência" (Althusser, 2003, p. 85), ou seja, a ideologia não é a representação real do sistema que opera sobre a vida das pessoas, mas a relação imaginária dessas pessoas com as relações reais sob as quais existem. Com essa concepção, Althusser (1999) nos indica que, no senso comum, a ideologia é uma concepção de mundo, mas que tal concepção não corresponde à realidade concreta e, portanto, trata-se de uma concepção imaginária.

Para que o sujeito se desloque, então, observamos através de Pêcheux (2014b, p. 138) o caráter comum entre as estruturas da ideologia e do inconsciente, quando ele diz que ambas dissimulam "sua própria existência no interior mesmo do seu funcionamento, produzindo um tecido de evidências 'subjetivas'. Para ele, é nesse ponto de evidência que se inicia o delineamento de uma teoria materialista do discurso, comparando a evidencia da existência do sujeito, como origem ou causa de si, com a evidência da transparência da linguagem, que designa que o dito só poderia ser dito e significado de uma forma. Esse jogo de evidências é chamado de efeito ideológico, em referência ao conceito já proposto por Althusser (2003), mas ampliado com esse entendimento por Pêcheux (2014b).

Nessa relação entre evidências, a evidência do sujeito e a evidência do sentido é onde se situa a interpelação. É por meio da interpelação ideológica, concebida como uma ilustração do "teatro da consciência" (Pêcheux, 2014b, p. 140), que podemos retomar a noção de que os indivíduos já são sempre 
sujeitos, pois já são sempre interpelados pela ideologia. É por meio da interpelação que o sujeito será convocado a se identificar - identificação simbólica e imaginária - como turista para que se desloque.

\section{3 “TRAE TUS COLORES!” OU TRAIA SUAS CORES?: PROBLEMATIZANDO O TURISMO LGBT}

Para esta exposição, selecionamos quatro sequências discursivas (SD), recortes realizados sobre a materialidade e que se mostraram ao nosso olhar em forma de estranhamentos. As sequências discursivas que compõem o corpus desta análise serão numeradas sequencialmente como SD1, SD2, SD3 e SD4.

O primeiro recorte sobre a materialidade refere-se à capa do folheto promocional, onde estão localizadas as duas primeiras sequências discursivas desta exposição. Considera-se, assim, como SD1 a imagem que preenche o fundo da metade superior da página (Figura 1) e SD2 as duas imagens que dividem a metade inferior da página (Figura 2).

A imagem que ocupa a metade superior da capa, SD1, expõe uma praça à noite e, portanto, iluminada por luz artificial. $\mathrm{O}$ folheto não indica a cidade exposta pela foto, portanto, nos permitimos supor que esta praça é rodeada por estabelecimentos comerciais e mais ao fundo prédios altos. Na medida em que afastamos o olhar da praça em direção ao fundo da imagem, essa perde luminosidade até atingir a escuridão. A luminosidade direciona toda a atenção para a praça, como lugar de identificação. Aqueles que ocupam a escuridão na imagem não pertencem à praça e vice-versa.

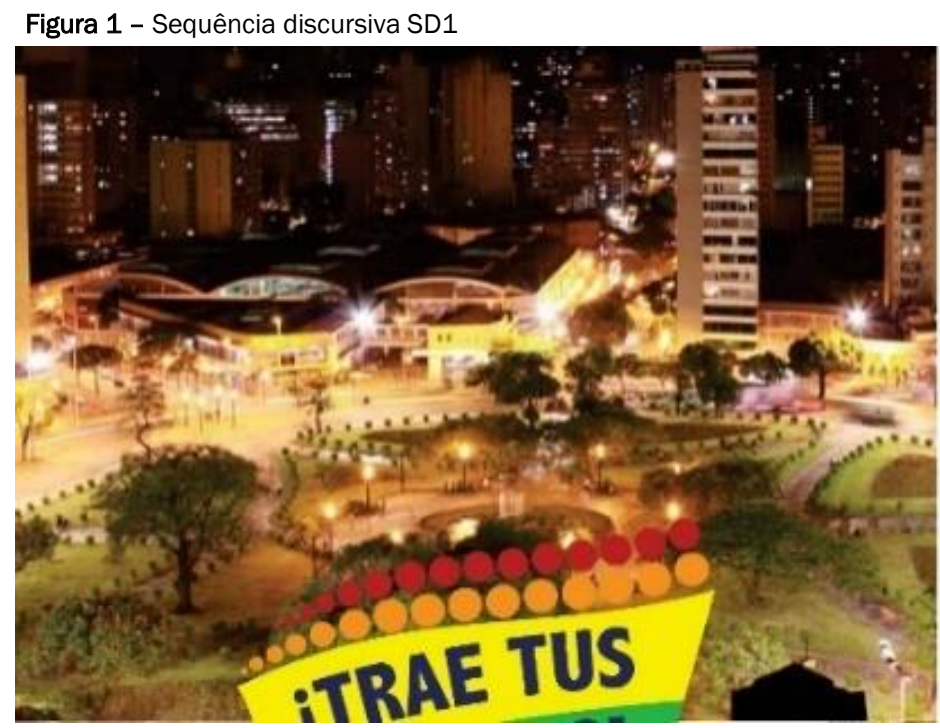

Fonte: Guiya Editora (2014, p. 1).

A imagem em questão, portanto, deixa explícito o local oferecido à apreciação e/ou visitação, a praça. Mais do que isso, a praça como aquilo que é e torna visível, onde podemos ver e ser vistos. A praça, como campo de trocas simbólicas, ao longo de toda sua materialidade histórica, social e cultural, é atrelada a um imaginário de (com)viver, estar junto (Gastal, 2006). Lugar público, a praça possui grande fluxo de pessoas durante o dia, utilizada para a prática de exercícios físicos, abrigo do sol sob as árvores, descanso, atividades de lazer ou simplesmente como percurso. Nas diferentes cidades, nos diferentes lugares, a praça assume diferentes usos, porém nunca deixa de ser um lugar de interação entre sujeitos.

Ao invés de pensar na imagem como um discurso, permitimo-nos ir além. Ao encontro de Orlandi (2004), propomos pensar o lugar representado, a praça, como um discurso, que é efeito de sentidos (Pêcheux, 2014a). Mais especificamente, propomos pensar na praça como um discurso que fala de/para os sujeitos LGBT. Iniciamos pelos questionamentos: por que uma praça? Por que uma praça à noite? Que sentidos são mobilizados em torno desse lugar? Que importância possui uma praça para ocupar a metade da capa do folheto de uma ação promocional direcionada aos sujeitos LGBT? Qual a relação de sentidos entre uma praça à noite e o sujeito LGBT? 
A partir desses questionamentos, começamos a escrever sobre uma folha de papel, contendo essa imagem, tudo aquilo que se destaca ao pensamento. Surgem os termos: praça, noite, prostituição, sexo, natureza, instinto, pegação (sic), violência. Essas palavras se relacionam no jogo significante instituído por um imaginário. Ao mesmo tempo em que essas palavras relacionam o corpo dos sujeitos produzindo sentidos sobre a praça, essa última produz sentidos sobre o corpo dos sujeitos. Ambiente natural em meio ao concreto urbano, os corpos que transitam pela praça entram em contato e se misturam a sua natureza, pois são parte dela. Essa relação entre o natural e o instintual permanece recalcada no ambiente urbano através das praças, onde é possível (re)entrar em contato com o pulsional.

Nesse lugar instintual, a inscrição do sujeito dividido entre a ordem imposta pela rotina do urbano e a desordem intrínseca do pulsional. A praça passa a significar o lugar de inscrição dos desejos impossíveis, censurados, marginais. A praça torna-se o palco da pulsão e do real, portanto, do incontrolável. Lugar do exercício da prostituição como um trabalho que só pode ser invisível, lugar de relações afetivas e sexuais para todas as pessoas inviabilizadas em suas sexualidades, lugar de drogadição para aqueles que encontram na alucinação um meio de deslocarem-se dos sofrimentos cotidianos, lugar de moradia para aqueles expulsos pela propriedade privada, lugar de práticas culturais inapropriadas para as casas de cultura e centros esportivos de alto rendimento. A praça, em sua essência e em sua materialidade histórica, é o lugar da vagabundagem por excelência. E já que:

O corpo dos sujeitos está atado ao corpo da cidade e estes são significados por essa ligação. E de tal modo se articulam que o destino de um não se separa do destino do outro, em suas inúmeras e variadas dimensões: material, cultural, econômica, histórica etc. 0 corpo dos sujeitos e o corpo da cidade formam um só. Nosso corpo, urbano, que se textualiza como um corpo de cidade, ocupa um espaço e é ocupado por ele (Orlandi, 2011, p. 695).

Dialeticamente, interpretamos a praça como um espaço de controle do desejo do sujeito pela ideologia dominante que o oferta como um objeto de desejo. A noite representa a censura daquilo que não pode ser visto à luz do dia, para que não haja abalo na organização do imaginário social, ficcional, garantindo a impossibilidade de reelaboração simbólica dos desejos desautorizados. Em torno da praça cola (sic) o significante do poder, pois é no entorno da praça que as instituições públicas e a igreja serão dispostas vigilantes daquilo que nela ocorre. A praça como a metáfora da vigilância/controle/censura sobre o desejo dos sujeitos.

Direcionando o olhar para a metade inferior da capa, onde se localiza SD2 (Figura 2), uma composição de duas imagens a divide. A primeira imagem, posicionada no canto inferior esquerdo, possui em primeiro plano um fragmento da bandeira do arco-íris sobre a areia de uma praia deserta, sem pessoas. No segundo plano da mesma imagem, surge o mar e uma montanha ao fundo. No último plano da imagem, o céu azul, nuvens e intensa luminosidade proporcionada pelo sol.

Figura 2 - Sequência discursiva SD2

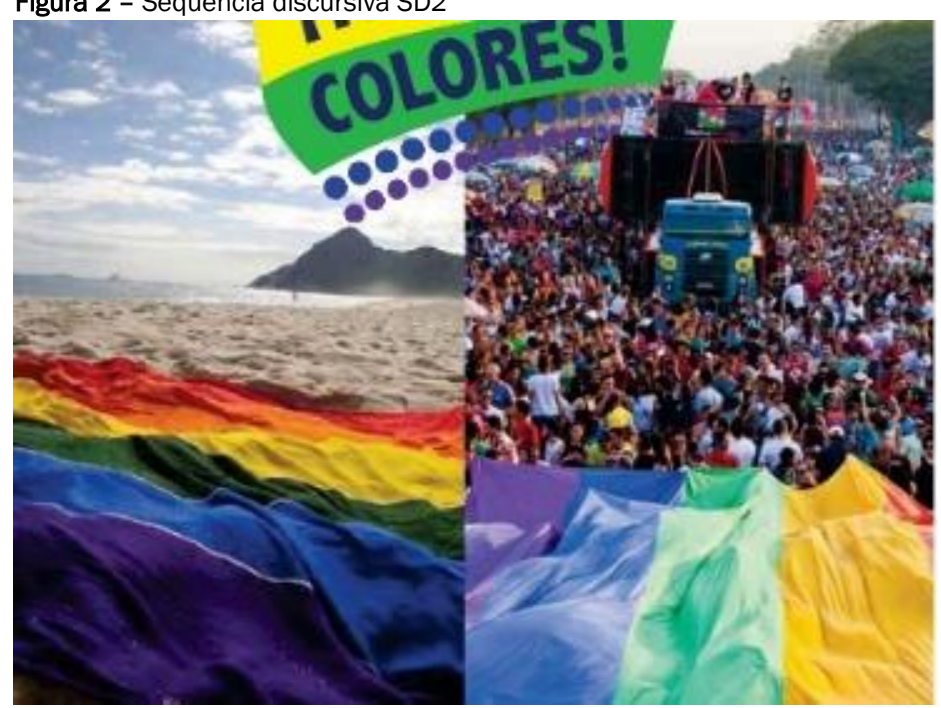

Fonte: Guiya Editora (2014, p. 1). 
A segunda imagem, localizada na metade inferior direita da capa, traz a ilustração daquilo que pode ser interpretado como uma Parada do Orgulho LGBT. Trata-se de uma grande via pública, completamente ocupada por pessoas, que podem ou não ser LGBT, que cercam um veículo usado para reprodução de som, sobre o qual também se encontram pessoas, provavelmente representantes do Movimento Social LGBT, organizadores do evento, representantes políticos, artistas e/ou performers. Todas essas pessoas e equipamentos seguem pela via pública, precedidos por uma gigante bandeira do arco-íris, símbolo deste movimento. A bandeira é o único elemento que permite identificar na imagem a representação de uma Parada do Orgulho LGBT, já que à imagem do Brasil também poderia significar o carnaval.

Ambas imagens dividem a metade inferior da página. Ambas imagens trazem uma bandeira do arco-íris em primeiro plano, lado a lado, de modo que uma bandeira é a extensão da outra. Transitando entre uma e outra e buscando compreender a relação entre as duas, percebemos aquilo que as diferencia: a primeira imagem não possui pessoas, a segunda uma multidão de pessoas. Vazio e cheio, deserto e ocupado. Que diálogo essas imagens estabelecem entre si e com o sujeito? Por quê?

Partimos pelo mesmo método sobre o qual empreendemos a análise da imagem da praça. A partir do questionamento sobre a relação dialógica entre o vazio e o cheio, o deserto e o ocupado, escrevemos todas as palavras que surgem ao pensamento em uma folha de papel com a SD2 impressa. Sobre a imagem da praia escrevemos: praia, natureza, deserto, calor, isolamento, exposição. Sobre a imagem da Parada escrevemos: festa, multidão, diversidade, corpos, desordem, indistinto, visibilidade. A partir dessas palavras, estabelecemos os traços significantes que dialogam entre elas.

A oposição vazio e cheio, deserto e ocupado, desliza para a relação entre o visível e invisível. O espaço vazio e deserto remete à ideia de isolamento, isento de perturbação e de pessoas que atrapalhem qualquer que seja a ação do sujeito naquele local. Ao mesmo tempo, o isolamento expõe o isolado, pois esse é mais visível e identificável quando destacado do espaço cheio e ocupado. Por sua vez, o espaço cheio e ocupado remete à ideia de ver e ser visto por todos, portanto, do visível. Contudo, na multidão, o todo coletivo toma a posição do singular, tornando o sujeito indistinto, não identificável, apagado pelo todo. 0 desejo do sujeito, visível ou invisível, torna-se controlável, contornável, manipulável.

O enunciador joga com as possibilidades de desejo do sujeito LGBT, antecipando-as em sua representação imaginária, simbolizando-as naquilo que enuncia. Todas as imagens da capa (SD1 e SD2) significam, ao mesmo tempo, visível e invisível, pela ocultação ou exposição dos corpos dos sujeitos. As imagens representam os espaços regulados para a inscrição do sujeito. Para o enunciador, é evidente que as imagens representam o modo de vida do sujeito LGBT: noite, (ex)posição, festa, interação. Corpos que interagem e se (ex)põem, na noite e na festa. (Ex)põem porque não podem se (in)porem. Para o sujeito interpelado, o assujeitamento surge como a única possibilidade de gozo, pelo jogo da evidência de si e dos sentidos, pela aceitação do reconhecimento de si na imagem formada pelo desejo do Outro. Esse Outro, no campo da Psicanálise e de nossas análises representa a ordem simbólica e não um outro sujeito.

Se o corpo do sujeito está atado ao corpo da cidade (Orlandi, 2004), se sujeito e cidade se produzem e se significam mutuamente, a oferta da cidade para os sujeitos representa, ela mesma, a alienação do sujeito diante de sua própria realidade. O sujeito tem a ilusão de que poderá alcançar a realização do desejo, pois sua identidade é externalizada na imagem do seu duplo. Nessa trama que estabelece a identificação imaginária do sujeito com a possibilidade de um gozo ofertado pelo Outro, é garantido o desconhecimento da sua dependência total em relação ao Outro (Žižek, 1992).

Por fim, retoma-se as questões que subentendem as formações imaginárias propostas para esta análise. A imagem antecipada do sujeito colocado em B para o enunciador, $I_{A}(B)$, se mostra através das imagens dispostas no segundo plano da capa (SD1 e SD2). Ao fazer a pergunta "quem você pensa que é o LGBT para Ihe falar assim?", se nota que os lugares representados pelas imagens mobilizam significantes cristalizados no imaginário social acerca dos desejos censurados. A praça à noite, a praia deserta e uma multidão de pessoas em torno de um caminhão de som, reproduzem o estereótipo sexualizado dos corpos em exposição. Expostos os corpos são sujeitados à interação de uns com os outros, como o fragmento de desejo que lhes é autorizado. Controlados por $\mathrm{I}_{\mathrm{A}}(\mathrm{A})$, esses corpos precisam, ao mesmo tempo, serem apagados, pois insurgem-se contra o princípio de identidade instituído. Portanto, não sendo possível negar totalmente a inscrição de seus desejos, você sendo quem eu penso que você é ( $\left.\mathrm{I}_{\mathrm{A}}(\mathrm{B})\right)$, lhe permito ser e estar, mas apenas 
à noite, em locais desertos ou em meio à multidão. Dessa forma garanto que você não será incomodado, nem incomodará ninguém.

Na segunda página do folheto, é apresentada uma composição de figuras geométricas, triangulares e coloridas ao fundo, e por um quadro branco centralizado. 0 quadro branco é utilizado como a caixa através da qual se estrutura um texto de quatro parágrafos. Para fins de análise, tomaremos apenas o texto como a sequência discursiva SD3, sobre a qual iremos nos debruçar a seguir. O texto da SD3 enuncia o que segue:

SD3: La diversidad en Brasil está presente en la música, la gastronomía, la geografía, la cultura y en su gente. Muy orgullosos de esa pluralidad, lo invitamos a conocer un país alegre, moderno y grandioso.

Somos una de las mayores economías del mundo, una sólida democracia, con bellezas naturales y grandes ejemplos de la creatividad humana en varias áreas.

Las ciudades de Rio de Janeiro, Brasilia y Belo Horizonte son pruebas de ese país fuerte, encantador y cada vez más inclusivo.

Somos una nación de colores, del arcoíris, símbolo internacional del segmento LGBT. Y será un gran honor recibir su energía, su diversidad, en fin, isus colores! (Guiya Editora, 2014, p. 2 , grifo nosso)

Conferimos destaque na SD3 a um conjunto de predicados utilizados pelo enunciador para, nos três primeiros parágrafos, descrever qualidades conferidas por ele ao Brasil. Também destacamos, no último parágrafo, outros três predicados que dizem respeito às qualidades atribuídas pelo enunciador ao sujeito a quem se dirige o enunciado. Por último, destacamos a expressão "nación de colores", como a expressão que estabelece uma relação de ligação entre os predicados que vêm antes dela com aqueles que vêm depois.

O Brasil é apresentado como o país da diversidade, pluralidade, alegria, modernidade, grandiosidade, beleza, criatividade, força, encantamento, inclusão, ou seja, como a nação das cores. O LGBT é descrito como aquele que possui energia, diversidade e cores. Esse conjunto de adjetivos formam uma família parafrástica no interior de SD3. Isoladamente ou somados, se prestam a descrever tanto o Brasil como o sujeito LGBT, passíveis, portanto, de deslizamentos entre si. É, como diz Pêcheux (2014a, p. 167), "no interior desta família que se constitui o efeito de sentido, assim como a relação a um referente que implique este efeito". Nosso referente, aqui, é o Brasil.

O Brasil, como referente, é apenas o objeto que complementa o verbo ser. Quem executa a ação do verbo é o sujeito, neste caso o sujeito LGBT. Assim, o efeito de sentidos produzido por essa matriz, implica em considerarmos que o sujeito LGBT é o Brasil. Implica, ainda, em considerarmos que, se o sujeito LGBT é Brasil, é também tudo aquilo que o Brasil é. A relação de paráfrase, dessa forma, alude para o sujeito que ele é isso e não outra coisa (evidência de si), assim como que o Brasil é aquilo e não outra coisa (evidência de sentidos).

Preso ao jogo das evidências, o sujeito é interpelado na trama das identificações simbólica e imaginária. Simbólica porque traduz o motivo pelo qual eu me identifico com aquilo que eu gostaria de ser, ou seja, quando eu tento simbolizar o meu desejo. Imaginária porque traduz aquilo que eu gostaria de ser para ser amado, ou seja, quando eu tento simbolizar o desejo do Outro que, não sendo o meu desejo, se desdobra em uma fantasia (Žižek, 1992). É nessa trama, produzida pela relação de paráfrase, em que se produzem os sentidos capazes de promover a identificação do sujeito com o enunciado e, portanto, seu assujeitamento.

Por isso, ao mesmo tempo em que o sujeito se identifica com o Brasil, se esquece que está se identificando com os enunciados apagados sobre si. Ao mesmo tempo em que o sujeito identifica o Brasil com seus próprios predicados, se esquece que existem outros predicados possíveis sobre o Brasil que não produziriam o mesmo efeito de sentidos a seu respeito, ou seja, outras características não tão boas assim. Como, exemplo, podemos citar o fato de que o Brasil liderava o ranking mundial de assassinatos da população LGBT em 2013 (Grupo Gay da Bahia, 2013) e 2014 (Grupo Gay da Bahia, 2014) e de que até os dias atuais a violência contra essa população não é tipificada como crime no Brasil.

O enunciador, também assujeitado pela ideologia na qual se inscreve, ao enunciar as características do Brasil, está enunciando as características do sujeito LGBT pela antecipação da imagem desse sujeito a partir 
do lugar que ocupa $\left(I_{A}(B)\right)$, mas também a partir do seu ponto de vista sobre o referente Brasil $\left(I_{A}(R)\right)$ e da sua projeção sobre o ponto de vista do sujeito LGBT acerca do referente Brasil $\left(I_{A}\left(I_{B}(R)\right)\right)$. A partir dessas antecipações, o enunciador é autorizado a selecionar, entre os dizeres possíveis e impossíveis, aqueles que irão produzir o efeito de sentidos necessário à identificação do sujeito LGBT com o Brasil e, mais além, à interpelação do sujeito LGBT como turista LGBT, cuja expressão máxima se dá sob a forma de seu deslocamento físico.

Como último recorte do corpus de análise a ser exposto, apresentamos a página vinte e dois do folheto promocional. Esta página traz cinco imagens como plano de fundo. Também apresenta um quadro branco que se sobrepõe ao fundo, funcionando como uma caixa de texto, onde são apresentados dois parágrafos escritos. Não consideraremos as imagens como sequências discursivas nesta análise. Tomamos o texto contido no quadro branco como SD4, apresentado a seguir:

\footnotetext{
SD4: ¡Las opciones de locales LGBT son muchas! Saunas, clubs, tiendas, bares, cafeterías... Para pasar increíbles momentos en Brasília, Belo Horizonte $(\mathrm{BH})$ y Rio de Janeiro, se ofrecen guías completas impresas conteniendo mapas, descripciones, precios y horarios de funcionamiento de los establecimientos arcoíris.

¡Y más aún! Las ciudades de Florianópolis (Floripa), Salvador, Recife y San Pablo también cuentan con esas guías impresas. Todas forman parte de la primera red nacional de guías de turismo gay en Brasil, lanzamiento de la Guiya Editora. (Guiya Editora, 2014, p. 22, grifo nosso)
}

Os destaques que propomos em SD4, mais especificamente aqueles realizados no primeiro parágrafo, dizem respeito aquilo que já foi apresentado na análise das SD1 e SD2, como a censura do desejo do sujeito. Nas imagens da capa, o enclausuramento do desejo do sujeito no espaço público, em sua materialidade histórica que significa e é significada pelo sujeito. Nesta sequência, SD4, o enclausuramento do desejo do sujeito no espaço privado, a autorização do gozo pela fetichização (Marx, 2017) da vida dos próprios sujeitos como mercadoria.

Queremos dizer que, se o inconsciente se estrutura em torno de uma falta e isso faz o sujeito desejar, o desejo pode ser interpretado como o produto do trabalho inconsciente do sujeito em torno dessa falta primordial. Se isso é possível de ser considerado, podemos considerar também que a transformação do desejo inconsciente em mercadoria, ou seja, a atribuição de um valor de troca sobre esse desejo (traduzida como disposição ou motivação para o consumo) representa a fetichização do desejo do sujeito. É necessário, contudo, ponderar que, sendo inconsciente e não-sabido para o sujeito, o desejo não é simbolizável, implicando que o processo de fetichização incida na alienação do sujeito diante do produto de seu trabalho inconsciente, isto é, na dissimulação do real não simbolizável em torno de uma fantasia.

Por qual motivo retomamos essa reflexão para a análise da SD4? Porque las opciones de locales LGBT, para além do enclausuramento dos sujeitos LGBT, representam a fetichização do desejo inconsciente do sujeito, alienado em consumidor, ou ainda, em turista. Representam também a observação do Turismo funcionando pela lógica do espetáculo, uma vez que ele "corresponde a uma fabricação concreta da alienação. [...] Quanto mais sua vida [do homem] se torna seu produto, tanto mais ele se separa da vida" (Debord, 1997, pp. 24-25).

Ao direcionar o gueto para a lógica do consumo, a materialidade histórica de constituição desses lugares, como lugares de resistência política, histórica, cultural e social dos sujeitos LGBT é retraída pela dissimulação da realidade que lhe é correspondente, através da fetichização do desejo e alienação do sujeito. Esse simulacro do espetáculo é o meio pelo qual o Turismo garante as condições de reprodução do capitalismo, antecipando aquilo que o sujeito irá ver, ouvir, comer, consumir, etc. O espetáculo como a "afirmação onipresente da escolha já feita na produção e o consumo que decorre dessa escolha" (Debord, 1997, pp. 14-15)

Os locais ofertados remetem ao imaginário da busca pela experimentação sexual, seja através da estetização do belo (tiendas), pela disposição dos corpos em interação/contato (bares, cafeterías), ou ainda pela oferta indireta do sexo (saunas, clubs). Todos os locais são uma (pre)disposição para o ato que define a sexualidade dissidente, o sexo. O sujeito LGBT é, portanto, enunciado a partir da antecipação à imagem de um estereótipo demarcado pelo estigma de sua sexualidade $\left(\mathrm{I}_{\mathrm{A}}(\mathrm{B})\right)$, pois é disso que se trata. Ou, de outra 
forma, como diz Soares $(2006$, p. 36) "todos os sentidos se voltam exclusivamente para as questões relacionadas à sexualidade [...]. 0 homossexual é seu sexo, nada além disso".

Questiona-se qual o efeito de sentidos poderíamos depreender, caso a frase em questão enunciasse o seguinte: as opções de locais heterossexuais são muitas! Saunas, boates, lojas, bares, cafés... Ao enunciarmos "o heterossexual vai à sauna" e "o gay vai à sauna", os significantes mobilizados ao termo "sauna" correspondem a sentidos diametralmente diferentes. É óbvio que o heterossexual vai à sauna por uma questão estética, de lazer ou relaxamento, por outro lado, é óbvio que o gay vai à sauna para pegação (sic) e sexo casual.

Estranhamos a sugestão de um segmento de Turismo heterossexual, pois, como propõe Soares (2006), a heterossexualidade é tratada como axioma, inquestionável $\left(I_{A}(A)\right)$, e, em consequência, sua posição antagônica ocupará a posição da dúvida, do questionamento. A heterossexualidade é discursivizada como normal, como o padrão, ao ponto de não ser passível de questionamentos. Não se estranha a segmentação de um Turismo para pessoas LGBT, precisamente porque essas pessoas ocupam posições de anormalidade, o que justificaria o seu "tratamento" de forma distinta, separada, segmentada. Se estranha, no entanto, o segmento de Turismo heterossexual porque tudo está autorizado aos heterossexuais, inclusive frequentar os locais LGBT.

Os sentidos deslizam porque as posições ocupadas pelos sujeitos envolvidos pertencem a diferentes formações discursivas reguladas por uma mesma formação ideológica capitalista. Diferentes formações discursivas porque aquilo que é autorizado dizer em uma posição, não é autorizado na outra. Mesma formação ideológica, porque a existência de uma pressupõe a existência da outra, isto é, os discursos autorizados em ambas antagonizam suas posições. É a possibilidade de deslizamento de sentidos entre uma e outra posição que demonstra a regulação do enunciado pela formação ideológica.

\section{CONSIDERAÇÕES FINAIS}

É preciso (re)ocupar o lugar da crítica no Turismo a partir do reconhecimento de um processo histórico que não rompeu com sua ideologia fundadora e que, portanto, não rompeu com o discurso que fala do sujeito antes que o sujeito fale. Não rompeu com esse lugar que enuncia a motivação de viagem do sujeito como uma necessidade de fugir, de se libertar, de partir para a busca de si mesmo, etc., mas que não questiona o porquê de o sujeito precisar fugir, se libertar e se encontrar. É preciso (re)ocupar o lugar da crítica no Turismo a partir do reconhecimento de um processo histórico que o forjou como um não-lugar para o sujeito. Não há Turismo sem interpelação e não há interpelação sem identificação, o sujeito é interpelado em turista e é assim que o deslocamento faz sentido.

Ao mesmo tempo em que o discurso no campo do Turismo atribui ao sujeito a motivação para viajar, um comportamento e perfil de consumo, nega ao sujeito a possibilidade de inscrição do seu desejo. Nega porque antecipa não só a projeção dessa motivação, comportamento e perfil, mas porque a partir disso diz onde o sujeito pode desejar e gozar, dissimulando a própria realidade do sujeito e também a realidade dos locais que serão visitados por ele.

Nessa direção, a segmentação de mercado constrói um perfil de turista como uma forma de falar do sujeito, de interpelá-lo, de identificá-lo. A imagem que o Outro oferece ao sujeito para dizer aquilo que o sujeito precisa ser para ser amado, aceito, respeitado, não violentado. Essa projeção não passa de uma imagem, que não produz real, mas pode ser ressimbolizada a partir dele. Esse é o choque que buscamos aqui. A não ser que a academia compreenda o Turismo exclusivamente como uma atividade econômica de distribuição de capital ao redor do planeta, não há outra via se não romper com a assimilação dos discursos produzidos pelo mercado em detrimento da própria capacidade de produzi-los.

Comumente, as produções científicas subsidiadas por modelos de pesquisas lógico-matemáticas, de oferta e demanda, não problematizam os discursos que falam acerca dos serviços ofertados ao turista LGBT, apenas que é vantajoso lhes ofertar algum tipo de serviço. Ao contrário disso, questionamos à academia e ao mercado: qual o tipo de atividade, serviço ou produto não pode ser ofertado ao LGBT por relacionaremse afetiva e sexualmente com alguém do mesmo sexo ou por terem uma expressão/identificação de gênero diferente daquela instituída e padronizada? 
Ratifica-se que não se trata, quando propomos a problematização do Turismo LGBT, de negar a busca pelo prazer sexual de sujeitos LGBT, mas problematizar a produção dessa demanda, como uma forma de controle sexual do sujeito LGBT. De problematizar a interpelação desses sujeitos em turistas pela apropriação de suas próprias produções psíquicas, culturais, sociais, históricas, etc. É preciso perceber que o lugar de enunciação do discurso turístico, na trama simbólica instituída pelo jogo das formações imaginárias, mobiliza os sentidos a partir dos quais a oferta turística sempre irá antecipar e projetar a imagem do sujeito a que se dirige o enunciado. Que essa antecipação é a fetichização do desejo inconsciente desse sujeito alienado em consumidor. Fetiche que roteiriza, segmenta, oferta, motiva, etc. Desprendido do seu real, o sujeito é aprisionado num roteiro ficcional que se retroalimenta de uma módica reprodução.

\section{AGRADECIMENTOS}

Agradecemos à Fundação de Amparo à Pesquisa do Estado do Rio Grande do Sul (FAPERGS) pela bolsa que financia, atualmente, nossa pesquisa de doutorado. Agradecemos à Coordenação de Aperfeiçoamento de Pessoal de Nível Superior (CAPES) pela bolsa que financiou a pesquisa de mestrado da qual derivou este trabalho.

\section{REFERÊNCIAS}

Althusser, L. (1999). Sobre a reprodução. Petrópolis, RJ: Vozes.

Althusser, L. (2003). Aparelhos ideológicos de Estado: Nota sobre os aparelhos ideológicos de Estado (AIE) (9a ed.). Rio de Janeiro: Edições Graal.

Angeli, E. A. (1999). Turismo GLS. In Ansarah, M. G. R. (Ed.), Turismo: Segmentação de mercado (pp. 183-208). São Paulo: Futura.

Avena, D. T., \& Rossetti, F. (2004). Homossexualidade, consumo, cidadania e hospitalidade. Caderno Virtual de Turismo, 4(2), 9-16. Recuperado de http://www.ivt.coppe.ufrj.br/caderno/index.php/caderno/article/view/53.

Campos, L. J. (2010). Imagens à deriva: Interlocuções entre a arte, a psicanálise e a análise do discurso. Tese de Doutorado. Programa de Pós-Graduação em Letras, Universidade Federal do Rio Grande do Sul. Recuperado de http://hdl.handle.net/10183/27958.

Chiochetta, A. S., \& Avena, D. T. (2006). Parada gay de São Paulo: evento de compromisso social ou uma grande festa na Avenida Paulista? Caderno Virtual de Turismo, 6(2), 11-18. Recuperado de http://www.ivt.coppe.ufrj.br/caderno/index.php/caderno/article/view/116.

Debord, G. (1997). A sociedade do espetáculo. Rio de Janeiro: Contraponto.

Dias, I., Oliveira, B., Lucian, R., Barbosa, M., \& Kovacs, É. (2009). Motivações do público homossexual na escolha dos destinos turísticos. Revista Acadêmica Observatório de Inovação do Turismo, 4(1), 1-20.

Freud, S. (1996a). A interpretação dos sonhos I (1900) (v. 4). Rio de Janeiro: Imago. Originalmente publicado em 1900.

Freud, S. (1996b). Os chistes e a sua relação com o inconsciente (1905) (v. 8). Rio de Janeiro: Imago. Originalmente publicado em 1905.

Freud, S. (1996c). Sobre a psicopatologia da vida cotidiana (1901) (v. 6). Rio de Janeiro: Imago. Originalmente publicado em 1901.

Gastal, S. (2006). Alegorias urbanas: O passado como subterfúgio. Campinas, SP: Papirus.

Grupo Gay da Bahia. (2013). Assassinato de homossexuais (LGBT) no Brasil: relatório 2013. Salvador: Grupo Gay da Bahia. Recuperado de https://homofobiamata.wordpress.com/estatisticas/relatorios/2013-2/.

Guiya Editora. (2014). Trae Tus Colores: Turismo LGBT (español). Recuperado de https://issuu.com/guiya-editora/docs/turismo_Igbt_brasil_espa_ol.

Guiya Editora. (n.d.). Quem somos. Recuperado de http://www.guiagaysaopaulo.com.br/quem-somos.

Henry, P. (2014). Os fundamentos teóricos da "análise automática do discurso" de Michel Pêcheux (1969). In Gadet, F. \& Hak, T. (Eds.), Por uma análise automática do discurso: Uma introdução à obra de Michel Pêcheux (5a ed., pp. 11-38). Campinas, SP: Editora da Unicamp.

Indursky, F. (2008). Unicidade, desdobramento, fragmentação: a trajetória da noção de sujeito em Análise do Discurso. In Mittmann, S., Grigoletto, E. \& Cazarin, E. (Eds.). Práticas Discursivas e identitárias: Sujeito \& Língua (pp. 9-33). Porto Alegre: Nova Prova.

Lacan, J. (1992). O seminário, livro 8: A transferência (1960-1961). Rio de Janeiro: Jorge Zahar. 
Lacan, J. (1998). A instância da letra no inconsciente ou a razão desde Freud. In Lacan, J. Escritos (pp. 96-103). Rio de Janeiro: Jorge Zahar.

Lacan, J. (1999). O familionário. In Lacan, J. O seminário, livro 5: As formações do inconsciente (1957-1958) (pp. 1129). Rio de Janeiro: Jorge Zahar.

Lacan, J. (2016). O seminário, livro 6: o desejo e sua interpretação (1958-1959) (tradução de Claudia Berliner). Rio de Janeiro: Jorge Zahar.

Lanzarini, R. (2013). A viagem liberadora: para além das fronteiras sociais da sexualidade. Revista Rosa dos Ventos: Turismo e Hospitalidade. 5(4), 548-558. Recuperado de http://www.ucs.br/etc/revistas/index.php/rosadosventos/article/view/2138.

Marx, K. (2017). O capital: critica da economia política: livro l: processo de produção do capital (2a. ed., tradução de Rubens Enderle). São Paulo: Boitempo.

Moesch, M. M. (2000). A produção do saber turístico. São Paulo: Contexto.

Moreira, M. G., \& Hallal, D. R. (2017). As Viagens e as Experiências de Fronteira na Transgressão do Armário Gay. Revista Rosa dos Ventos: Turismo e Hospitalidade. 9(1), 133-155. DOI: http://dx.doi.org/10.18226/21789061.v9i1p133

Oliveira, L. A. (2002). Turismo para Gays e Lésbicas: Uma viagem reflexiva. São Paulo: Roca.

Oliveira, L. A. (2016). Turismo Pós-moderno: o segmento LGBT no Brasil. Revista Turismo: Estudos \& Práticas (RTEP/UERN), 5(1), 40-56. Recuperado de http://periodicos.uern.br/index.php/turismo/article/view/1963.

Orlandi, E. P. (2004). Cidade dos sentidos. Campinas, SP: Pontes.

Orlandi, E. P. (2010). Análise de discurso: princípios e procedimentos (9a ed.). Campinas, SP: Pontes.

Orlandi, E. P. (2011). A casa e a rua: uma relação política e social. Educação \& Realidade, 36(3), 693-703. Recuperado de http://seer.ufrgs.br/index.php/educacaoerealidade/article/view/18491.

Pêcheux, M. (2014a). Análise Automática do Discurso (AAD-69). In Gadet, F. \& Hak, T. (Eds.), Por uma análise automática do discurso: uma introdução à obra de Michel Pêcheux (5a ed., pp. 59-158). Campinas, SP: Editora da Unicamp.

Pêcheux, M. (2014b). Semântica e discurso: Uma crítica à afirmação do óbvio (5a ed.). Campinas, SP: Editora da Unicamp.

Pêcheux, M., \& Fuchs, C. (2014). A propósito da Análise Automática do Discurso: atualização e perspectivas (1975). In Gadet, F. \& Hak, T. (Eds.), Por uma análise automática do discurso: Uma introdução à obra de Michel Pêcheux (5a ed., pp. 159-250). Campinas, SP: Editora da Unicamp.

Sanches, T. C., Mancini, L. A., \& Nascimento, M. A. N. (2011). Turismo GLS e o perfil do seu público consumidor na região norte do Paraná. Revista Turismo Visão e Ação - Eletrônica, 13(1), 81-95. DOI: http://dx.doi.org/10.14210/rtva.v13n1.p81-95

Soares, A. S. F. (2006). A homossexualidade e a AIDS no imaginário de revistas semanais (1985-1990). Tese de doutorado, Universidade Federal Fluminense). Recuperado de http://www.bdtd.ndc.uff.br/tde_busca/arquivo.php?codArquivo $=835$.

Tadioto, M. V. (2016). O lugar discursivo do sujeito no segmento turístico GLS. Dissertação de mestrado. Programa de Pós-Graduação em Turismo e Hospitalidade, Universidade de Caxias do Sul. Recuperado de https://repositorio.ucs.br/xmlui/handle/11338/1679.

Trevisan, J. S. (2006). Turismo e orientação sexual. In Brasil. Ministério do Turismo. Turismo Social: Diálogos do Turismo, uma viagem de inclusão (pp. 139-177). Rio de Janeiro: IBAM.

Trigo, L. G. G. (2009). Ascenção do prazer na sociedade atual: Turismo GLS. In Panosso Netto, A. \& Ansarah, M. G. R. (Orgs.). Segmentação do mercado turístico: estudos, produtos e perspectivas (p. 141-163). Barueri, SP: Manole.

Žižek, S. (1992). Eles não sabem o que fazem: O sublime objeto da ideologia. Rio de Janeiro: Jorge Zahar.

\section{Informações dos autores}

\section{Maicon Gularte Moreira}

Mestre em Turismo e Hospitalidade (PPGTURH/UCS). Doutorando em Turismo e Hospitalidade (PPGTURH/UCS), com bolsa de pesquisa da Fundação de Amparo à Pesquisa do Estado do Rio Grande do Sul (FAPERGS).

Contribuição: definição do problema de pesquisa e objetivos, desenvolvimento da proposição teórica, realização da revisão bibliográfica e fundamentação teórica, escolha dos procedimentos metodológicos, revisão crítica do manuscrito, redação do manuscrito, adequação do manuscrito às normas da RBTUR.

Lattes: http://lattes.cnpq.br/7209077042280859. 
E-mail: maicongmoreira@gmail.com.

ORCID: http://orcid.org/0000-0003-1794-9856.

\section{Luciene Jung de Campos}

Doutora em Estudos da Linguagem: teorias do texto e do discurso (PPGLET/UFRGS). Professora adjunta do Centro de Humanidades (UCS). Professora e pesquisadora do corpo permanente do Programa de Pós-Graduação em Turismo e Hospitalidade (UCS).

Contribuição: orientação do trabalho, indicação de bibliografia, definição do problema de pesquisa e objetivos, discussão dos conceitos, escolha dos procedimentos metodológicos, discussão da estrutura do trabalho, revisão teórico-conceitual do artigo.

Lattes: http://lattes.cnpq.br/1151177602559882.

E-mail: ljungdecampos@gmail.com.

ORCID: http://orcid.org/0000-0002-7427-742X. 